\title{
The Biotrophic, Non-Appressorium-Forming Grass Pathogen Claviceps purpurea Needs a Fus3/Pmk1 Homologous Mitogen-Activated Protein Kinase for Colonization of Rye Ovarian Tissue
}

\author{
G. Mey, ${ }^{1}$ B. Oeser, ${ }^{1}$ M. H. Lebrun, ${ }^{2}$ and P. Tudzynski ${ }^{1}$ \\ ${ }^{1}$ Institut für Botanik, Westfaelische Wilhelms-Universitaet, Schlossgarten 3, D-48149 Muenster, Germany; ${ }^{2}$ UMR 1932 \\ CNRS-Aventis, Physiologie Cellulaire Végétale, Aventis Crop Science, 14 rue Pierre Baizet, F-69009 Lyon, France
}

Submitted 5 September 2001. Accepted 31 December 2001.

Claviceps purpurea is a common pathogen of a wide range of grasses and cereals that is able to establish a stable, balanced interaction with its host plant and is considered a biotroph. It does not form special penetration structures such as appressoria. To study the signaling processes involved in this special host-pathogen interaction, we have cloned a gene, cpmk1, encoding a mitogen-activated protein (MAP) kinase that shows significant homology to Fus3 of Saccharomyces cerevisiae and to pmk1 of Magnaporthe grisea. Using a gene-replacement approach, we isolated a $\Delta$ cpmk1 mutant and characterized it in detail. Loss of CPMK1 has no obvious effect on vegetative properties (such as growth rate, morphology, and conidia formation); however, infection tests on rye show that the mutant is unable to colonize rye tissue, i.e., it appears to be completely nonpathogenic. Complementation of the mutant with a wild-type copy of cpmk1 fully restores its pathogenicity, confirming that this MAP kinase is essential for infection of rye by $C$. purpurea. Transformation of the $\Delta p m k 1$ mutant of $M$. grisea with a complete copy of cpmk1 (including the $C$. purpurea promoter) fully restored its ability to form appressoria and its pathogenicity on barley. Although both fungi drastically differ in their pathogenic strategies, this result indicates that the signal pathway involving CPMK1 is highly conserved.

Claviceps purpurea is a ubiquitous pathogen of grasses and cereals that infects young florets and replaces the plant's ovarian tissue with sclerotia. The fungus is able to penetrate the plant's cuticle without the help of specific infection structures such as appressoria. Its intracellular growth follows the path of the pollen tube until it reaches the ovary base, where it taps into the vascular tissue. Although it can be easily grown in axenic culture, it is considered to be a biotroph, since it causes only limited host cell death during the colonization phase. It is able to maintain a continuous flow of phloem exudates for the production of conidia-containing honeydew (Tenberge 1999; Tudzynski et al. 1995). We have recently addressed several aspects of this specialized host-pathogen interaction by a combined cytological, biochemical, and molecular genetic approach involving, for instance, the role of cell wall-degrading enzymes (Giesbert et al. 1998; Müller et al. 1997; Tenberge et al. 1996; ten Have et al. 2001) and active-oxygen-scavenging

Corresponding author: P. Tudzynski; E-mail: tudzyns@uni-muenster.de systems (Garre et al. 1998a, 1998b). Furthermore, we have initiated a broad, random approach to analyze infection-phasespecific gene expression, based on expressed sequence tag (EST) data and differential cDNA screening (Oeser et al., in press). We are particularly interested in the factors controlling the very early steps of infection, the directed growth in the plant tissue, and the establishment of a balanced interaction. As signal transduction is involved in all of these processes, we have initiated analyses of signal-transduction pathways in $C$. purpurea.

Signal pathway components are highly conserved within eukaryotic organisms, ranging from lower fungi to higher eukaryotes. Because of this high degree of homology, many fungal genes encoding components of such systems are known. In several host-pathogen systems, specific signaling components involved in the interaction have been identified, including subunits of heterotrimeric $G$ proteins, components of the cyclic AMP (cAMP) pathway, or protein kinases (Lengeler et al. 2000). Especially members of the mitogen-activated protein (MAP) kinases have been shown to play an essential role in the early stages of infection in several plant-pathogenic fungi (Xu 2000). We used degenerate primers to clone a MAP kinase (MAPK) gene from C. purpurea (cpmkl); by targeted deletion and complementation, it was shown that this gene is essential for the penetration and colonization of host tissue by $C$. purpurea. In addition, the cpmkl gene can complement a mutant of the orthologous gene from Magnaporthe grisea ( $p m k 1)$ and restore its ability to form appressoria and its pathogenicity. Thus, the signaling pathway containing cpmkl is highly conserved between these two fungi, even though they have completely different pathogenic strategies.

\section{RESULTS}

Isolation and characterization of the cpmk1 gene from $C$. purpurea.

Degenerate primers based on the sequences of the $M$. grisea pmkl and Aspergillus nidulans mpkB genes were used to amplify a 490-bp genomic fragment from $C$. purpurea, the deduced peptide sequence of which is $95 \%$ identical to the PMK1 protein. The polymerase chain reaction (PCR) product was used as a probe to screen a C. purpurea genomic library. Of the 6,000 lambda clones screened, seven clones hybridized to the PCR probe and were characterized further. Restriction map analyses revealed a common 6.9-kb BamHI fragment. This fragment was subcloned into pUC19, yielding plasmid pMKB2, 
and sequenced. It contains an open reading frame of 1,406 bp, which is interrupted by three introns of 118, 107, and $116 \mathrm{bp}$ (confirmed by cDNA sequencing, discussed below).

The 490-bp PCR fragment was also used as a probe to screen a $C$. purpurea cDNA library. Two cDNA clones hybridizing to the probe were further purified and sequenced. The transcription appeared to be initiated -397/-373 bp upstream of the predicted start codon, and only one major transcription termination site was found $+352 /+366$ bp downstream of the stop codon (data not shown). The coding sequences of the cDNA clones are identical to the genomic exons of the gene, designated cpmk1 (laviceps purpurea MAP kinase 1 ). The sequence of cpmkl is available under GenBank accession number AJ318517.

The deduced peptide sequence, CPMK 1 , is $97 \%$ identical to CGK1 from Colletotrichum gloeosporioides and to FMK1 from Fusarium oxysporum f. sp. lycopersici and is $96 \%$ identical to PMK1 from $M$. grisea. Phylogenetic analyses showed that CPMK1 belongs to the same group as the protein Fus3 from Saccharomyces cerevisiae and the other fungal Fus3 homologues (Fig. 1). S. cerevisiae MAPK Slt2 and Hog1 and their fungal homologs, which are involved in the pathways responsible for the maintenance of cell wall integrity and the response to osmotic stress, segregate into two different phylogenetic groups.

Southern blot analyses using cpmkl cDNA as a probe under low stringency conditions revealed only one 8-kb EcoRI fragment and two HindIII fragments of $5 \mathrm{~kb}$ and $0.9 \mathrm{~kb}$ in the wildtype strain 20-1 (data not shown). This is consistent with the presence of a single copy of the cpmkl gene in the genome of C. purpurea.

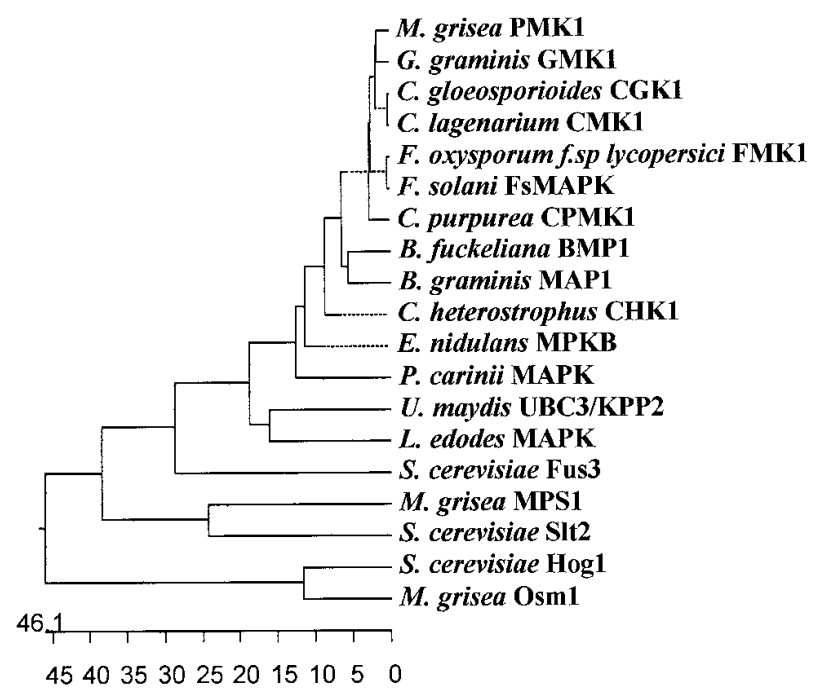

Fig. 1. Comparison of CPMK1 from Claviceps purpurea to other fungal mitogen-activated protein (MAP) kinases. The deduced peptidic sequence of cpmkl from C. purpurea (GenBank accession no. AJ318517) was compared with the MAP kinases PMK1 (U70134), MPS1 (AF020316), and OSM1 (AF184980) from Magnaporthe grisea; GMK1 from Gaeumannomyces graminis (AF258529); CGK1 from Colletotrichum gloeosporioides (AB047033); CMK1 from Colletotrichum lagenarium (AF174649); FMK1 from Fusarium oxysporum f. sp. lycopersici (AF286533); FSMAPK from Fusarium solani (U52963); BMP1 from Botrytis cinerea (AF205375); MAP1 from Blumeria graminis (AF301165); CHK1 from Cochliobolus heterostrophus (AF178977); MPKB from Emericella nidulans (AF198118); MAPK from Pneumocystis cariniii (AF043941); Ubc3/KPP2 from Ustilago maydis (AAF09452/AAF15528); MAPK from Lentinula edodes (AF173376); and Fus3 (M31132), Slt2 (X59262), and Hog1 (L06279) from Saccharomyces cerevisiae. The phylogram was constructed with the MegAlign program (DNA Star, Madison, WI, U.S.A.). cpmk1 Is expressed in planta.

Reverse-transcription (RT)-PCR analyses were performed in order to determine whether cpmkl is expressed during rye infection. A 465-bp PCR fragment was amplified with the primers $\mathrm{K} 9$ and $\mathrm{K} 10$ (Fig. 2A) and a cDNA clone as the template (Fig. 2B, lane 2). Because of the presence of two introns in this region, a longer fragment $(690 \mathrm{bp})$ was amplified with the same primer pairs and genomic DNA as the template (Fig. 2B, lane 1). RT-PCR analyses were performed with the primers K9 and K10 and with mRNA extracted from rye infected with the C. purpurea wild-type strain for 5, 10, 15, and 20 days. The PCR products, separated with an agarose gel, were difficult to detect by using ethidium bromide staining. Hybridization with a cpmkl cDNA probe revealed the presence of the predicted 465-bp fragment at 10, 15, and 20 days postinoculation (dpi) (Fig. 2B, lanes 4 to 6), corresponding respectively to the stages of honeydew production, differentiation, and maturation of the sclerotia (the upper band occurring in lanes 4 and 6 is derived from contaminating genomic DNA in these specific RNA samples; note the same bands in the control [Fig. 2C]). The expression level of cpmkl seems to reach a maximum at $10 \mathrm{dpi}$. No signal could be detected with the mRNA extracted at 5 dpi (Fig. 2, lane 3). The lack of expression of cpmkl at this stage could be attributed to both the low ratio of fungal/plant mRNA and the general low expression level of cpmkl. By using a comparable RT-PCR approach, transcripts of the class II hydrophobin gene $c p h l$ (S. Moore and P. Tudzynski, unpublished data) were detected in all stages of rye infection and appeared, according to ethidium bromide staining of the amplification products, to be much more abundant than the cpmkl transcripts (Fig. 2C). cpmkl Appears thus to be expressed in planta, though at a very low level.

\section{CPMK1 is essential for pathogenicity.}

Mutant strains lacking an active cpmkl gene were generated using the gene-replacement vector pMIR (Fig. 3A). Transformants were selected on medium containing phleomycin, and their genomic DNA was subjected to PCR with the primers K5 and pAN2 (Fig. 3A). Two out of the 246 transformants analyzed exhibited the 1,320-bp fragment, consistent with the replacement of cpmkl with the phleomycin resistance construct. The $\Delta$ cpmk1 transformants called M1.5 and M1.245 were genetically purified using single-spore isolation. One isolate of each knock-out transformant, lacking the wild-type copy of the cpmk1 gene as revealed by PCR with the primers K5 and K7 (Fig. 3A), was subjected to Southern blot analysis with the left flank of the replacement vector as a probe (Fig. 3B). A 3.6-kb PstI fragment and a 1.3-kb KpnI fragment corresponding to cpmkl were revealed in both the wild-type strain and the transformant M1.28 carrying an ectopic insertion of the replacement construct (Fig. 3B, lanes 1, 4, 5, and 8). Neither signal was detected in the knock-out transformants (Fig. 3B, lanes 2, 3, 6, and 7). Instead, consistent with a replacement event, a $1.2-\mathrm{kb}$ PstI fragment was detected in the M1.5 and M1.245 strains. However, the presence of an additional 5-kb PstI fragment (Fig. 3B, lane 3) revealed that the M1.245 transformant does contain an additional ectopic copy of the replacement construct. Both $\Delta c p m k 1$ strains exhibited KpnI fragments longer than the expected 5.4-kb fragment, indicating that the KpnI site on the right flank of the cpmkl locus was lost during the recombination process.

Pathogenicity of the $\Delta c p m k 1$ mutant strain M1.5 (carrying no additional ectopic integration) was assayed by using rye infection tests. Rye flowers were inoculated with conidial suspension of the M1.5, M1.28 (an ectopic transformant carrying an intact cpmkl gene), and wild-type strains and monitored for 3 weeks. Honeydew was visible on the rye florets infected with 
the M1.28 and 20-1 strains after 6 to 9 dpi. In assays with both strains, sclerotia fully differentiated within $21 \mathrm{dpi}$ (Fig. 4A to C). In contrast, no disease symptoms could be observed on the flowers infected with the $\Delta c p m k 1$ strain (Fig. 4A). Some of the infected flowers even produced seeds, indicating that the development of the plant is not affected by the presence of the fungus. A fluorescent microscopical analysis of ovaries infected with the cpmkl mutant did not reveal any fungal hyphae within the style tissue at $5 \mathrm{dpi}$, whereas in the wild-type infection, the hyphae penetrated the stigmatic hairs soon after germination and grew downward to the style (Fig. 5A). Later, massive hyphal bundles could be observed growing within the style toward the ovary (data not shown). In the mutant, only epiphytic hyphae could be detected growing on the outer surface of the stigma (Fig. 5B to D). Although the mutant conidia could germinate on the stigma surface, they obviously were unable to penetrate.

In order to determine whether the deletion of cpmkl only affects the ability of the mutant to penetrate the host tissue, spores of the mutant M1.5 were introduced inside the floret tissue with a needle. No symptoms of the ergot disease appeared and the $\Delta c p m k l$ transformant remained completely nonpathogenic, whereas the same infection conditions led to a normal time course of disease development with the ectopic transformant M1.28 and the wild-type strain (data not shown). Obviously, the mutant is also significantly impaired in colonizing the host tissue after wounding.

To prove that the lack of pathogenicity of the M1.5 strain is because of the deletion of cpmk1, complementation experiments were performed. A 3.6-kb genomic fragment, including the cpmkl coding region and $1.0 \mathrm{~kb}$ and $1.1 \mathrm{~kb}$ of the cpmkl promoter and terminator regions, respectively, was cloned into the $\mathrm{XbaI}$ and $\mathrm{SacI}$ sites of the pCB1635 vector, which carries a glufosinate resistance cassette (bar). The plasmid obtained, pM1CXS, was used to transform the C. purpurea $\Delta$ cpmkl mutant strain M1.5. Transformants were selected on glufosinatecontaining plates. Twenty transformants were analyzed in detail; they were shown to be both phleomycin and glufosinate resistant, indicating that they carry both the replacement and the complementation constructs. PCR analyses with the primers $\mathrm{K} 9$ and $\mathrm{K} 12$ revealed that 18 transformants contain the complete cpmkl coding region (data not shown). Two of them (M1C.6 and M1C.8) were further analyzed by Southern hybridization with the pM1P EcoRI insert as a probe. A $3.4-\mathrm{kb}$ $E c o$ RV fragment and a 1.0-kb PstI fragment, characteristic for the replacement of cpmkl with the phleomycin resistance cassette, were detected in the M1.5 recipient strain and in the M1C.6 and M1C.8 transformants (data not shown). Both the M1C.6 and M1C.8 strains showed one 2.5-kb EcoRV fragment corresponding to the cpmkl gene under the control of its own promoter and terminator regions. They carry several copies of the complementation vector, as revealed by the presence of several Pst I fragments hybridizing to the probe. The $4.4-\mathrm{kb}$ EcoRV fragment and the 3.6-kb PstI fragment, corresponding to the wild-type cpmkl gene, were detected in the 20-1 strain but not in the M1C.6, M1C.8, and M1.5 strains, indicating that no cross-contamination of the transformants with the wild-type strain occurred (data not shown).

Conidial suspensions of the M1C.6 and M1C.8 strains were used to infect rye flowers. The honeydew production started between 6 and 8 dpi. The spores rescued from the honeydew produced by both transformants were shown to be both phleomycin and glufosinate resistant, i.e., the positive infection was not due to a wild-type contamination. As in infection with the wild-type strain, sclerotia differentiated within 21 dpi (Fig. 4D). The time course of infection was comparable to the one obtained with the wild-type strain 20-1 (Fig. 4D); M1C.6 and
M1C.8 thus appear to be as pathogenic as the wild-type strain. This demonstrates that cpmkl complements the pathogenicity defect of the $\Delta c p m k 1$ mutant M1.5 and confirms that cpmkl is essential for the pathogenicity of C. purpurea on rye.

cpmk1 Restores the appressoria formation and pathogenicity functions of an $M$. grisea $\triangle p m k 1$ mutant.

In order to determine whether the MAP kinase CPMK1 from C. purpurea, a non-appressoria-forming fungus, can restore the functions of its orthologue PMK1 in M. grisea, the pM1CXS plasmid, carrying cpmkl under the control of its own regulatory regions, was introduced into the $M$. grisea $\Delta p m k 1$ mutant strain nn78. The transformants were selected on glufosinatecontaining plates. As a control, $\Delta p m k 1$ transformants carrying
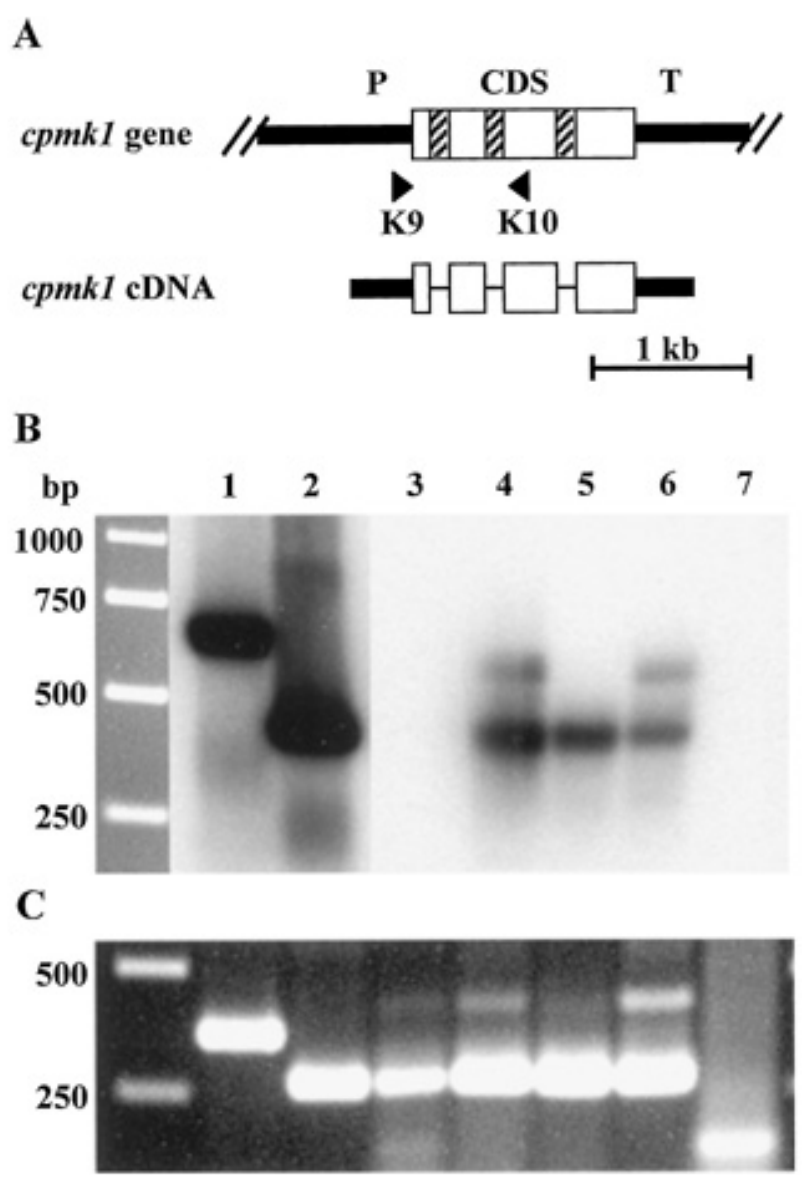

Fig. 2. cpmk1 Expression during infection of rye by Claviceps purpurea. A, Scheme of the structure of the cpmkl gene and cDNA showing the positions of the coding sequence (CDS, white box), promoter (P), and terminator $(\mathrm{T})$ regions. The introns are represented by hatched boxes. The positions of the primers $\mathrm{K} 9$ and $\mathrm{K} 10$ used for reverse-transcription-polymerase chain reaction (RT-PCR) are indicated with black triangles. B, RT-PCR analysis of cpmk1: PCR was performed with genomic DNA (lane 1) and a cpmk1 cDNA plasmid (lane 2) as a control. First-strand cDNAs were generated from total RNA extracted from rye ovaries infected for 5, 10, 15, and 20 days (lanes 3 to 6 , respectively) and from noninfected rye ovaries (lane 7). This cDNA was then used as a template for PCR with the gene-specific primers K9 and K10. To prove the identity of the PCR products, the agarose gel was blotted on nylon membrane and hybridized with a ${ }^{32} \mathrm{P}$-labeled cpmkl probe. The GeneRuler 1-kb DNA Ladder (MBI Fermentas, St. Leon-Rot, Germany) (left side) was used to estimate the size of the PCR products. C, Control RT-PCR: the same templates as in B were used for RT-PCR with a primer pair specific for a gene expressed constitutively in planta, $c p h l$, coding for a class II hydrophobin (S. Moore and P. Tudzynski, unpublished data). A lowmolecular-weight, unspecific amplication product appears in lane 7. 
the pCB1635 vector containing only the glufosinate resistance cassette were generated in parallel.

Southern blot analyses, with a cpmkl cDNA clone as a probe, showed that the $\Delta p m k 1 / c p m k 1$ transformants $\mathrm{T} 1$ to $\mathrm{T} 4$ carry the 2.5-kb EcoRV fragment characteristic for the cpmkl gene. Only one $X b a \mathrm{I}$ fragment was revealed in the strains T1 and $\mathrm{T} 2$, indicating that only one copy of the complementation vector integrated into the genome. No signal could be detected in the $\Delta p m k 1$ recipient strain, the transformants containing the pCB1635 vector, and the wild-type strain (data not shown).

$\mathbf{A}$

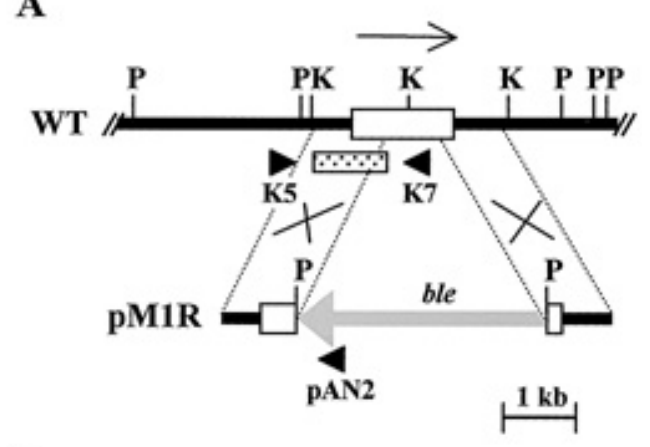

B

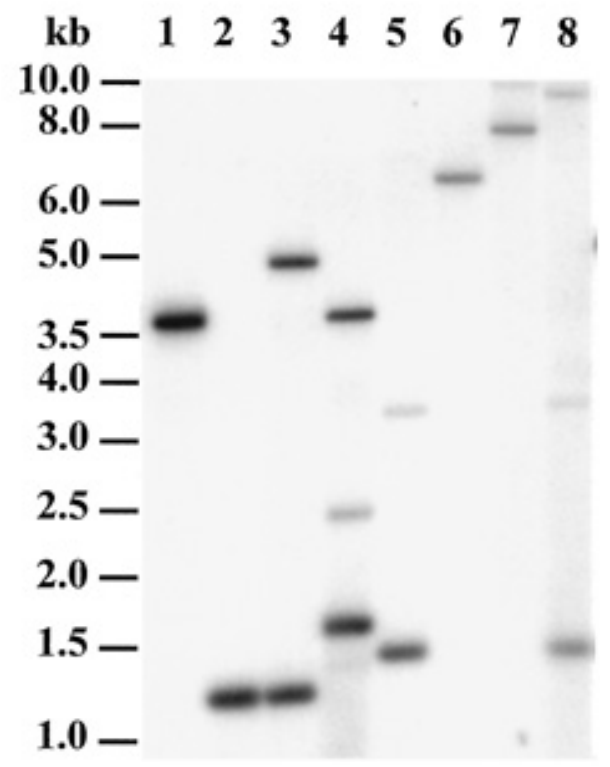

Fig. 3. Inactivation of $c p m k 1$ using a gene-replacement approach. A, The replacement vector $\mathrm{pM} 1 \mathrm{R}$ was constructed by cloning the $3^{\prime}$ and $5^{\prime}$ parts of cpmk1 on each side of a phleomycin resistance cassette (ble) in the pAN8-1UM plasmid (details in text). The resistance cassette, excised with a SacII-KpnI restriction, was used to transform the Claviceps purpurea wild-type strain 20-1 (top). $\Delta c p m k 1$ Mutants were generated following the disruption of the wild-type gene (WT) by homologous recombination through a double-crossover event. The cpmk1 coding sequence is represented with a white box. The sense of transcription of cpmkl is indicated with a black arrow. The grey arrow shows the orientation of the phleomycin resistance cassette within the replacement construct. The positions of the primers $\mathrm{K} 5, \mathrm{~K} 7$, and pAN2, used for the detection of cpmk1 wild-type copy and for the identification of the $\Delta c p m k 1$ mutants, respectively, are indicated with black triangles. Abbreviations for restriction enzymes: $\mathrm{P}=P s t \mathrm{I}$ and $\mathrm{K}=K p n \mathrm{I}$. B, Southern blot analysis of genomic DNA extracted from the wild-type strain 20-1 (lanes 1 and 5), the $\Delta$ cpmk1 mutants M1.5 (lanes 2 and 6) and M1.245 (lanes 3 and 7), and the transformant M1.28 carrying an ectopic integration of the replacement construct (lanes 4 and 8). The DNA was digested with PstI (lanes 1 to 4 ) and KpnI (lanes 5 to 8). The blot was probed with the 1-kb SacII-NotI fragment from cpmkl corresponding to the $3^{\prime}$ flank of the replacement vector (dotted box shown in $\mathbf{A}$ ).
Appressoria differentiation tests were performed in vitro with two different hydrophobic surfaces, plastic slides and onion epidermis. The germinating spores of the transformants $\mathrm{T} 1$ to T4 (carrying the M1CXS vector) were able to differentiate melanized appressoria comparable to the ones obtained with the wild-type strain on both surfaces (Fig. 6A, C, and D). In contrast, the spores of the transformants carrying the pCB1635 vector and the $\Delta p m k 1$ recipient strain produced long germ tubes but did not develop any infection structure (Fig. 6B). Thus, the expression of the heterologous gene cpmkl from $C$. purpurea restores the appressoria formation function in the $M$. grisea $4 p m k 1$ mutant strain.

Four transformants carrying cpmkl were tested for their ability to infect barley. Conidial suspensions of the $\Delta p m k 1 / \mathrm{cpmkl}$ strains T1 to T4 were spread on the surface of barley leaves. Infection tests using the $\Delta p m k l$ recipient strain, a transformant carrying the pCB1635 vector alone, and the wild-type strain Guy 11 were performed in parallel as a control. Comparable lesions were observed at $5 \mathrm{dpi}$ on the leaves infected with the $\Delta p m k / c p m k l$ transformants and with the wild-type strain (Fig. 7). No lesions developed on the leaves infected with the $M$. grisea $\Delta p m k 1$ mutant strain and with the transformants carrying the vector pCB1635 (Fig. 7).

These data prove that the cpmkl gene from C. purpurea, under the control of its own $5^{\prime}$ and $3^{\prime}$ regulatory regions, complements the $\Delta p m k l$ deficiency in $M$. grisea.

\section{DISCUSSION}

MAP kinases, a special family of serine/threonine protein kinases, are known to mediate the adjustment of intracellular activities of eukaryotic cells to environmental changes; they are activated by a MAP kinase cascade that has been shown to be highly conserved in a wide variety of eukaryotic organisms (Schaeffer and Webber 1999). In S. cerevisiae, five MAP kinase-mediated signal-transduction pathways have been identified, three of which have been shown to be also active in filamentous fungi: Fus3/Kss1 is involved (in $S$. cerevisiae) in mating responses and filamentous growth, S1t2 is responsible for cell integrity, and Hog1 is involved in stress response (especially high osmotic pressure). In the phytopathogenic filamentous fungus $M$. grisea, homologs of these three MAP kinases have been described: $p m k 1$ ( $\triangleq$ Fus3), osml (스og1), and $m p s 1$ ( $\triangleq$ Slt2). Only pmkl and $m p s 1$ have been shown to be involved in the pathogenicity of this fungus: pmkl mutants are impaired in appressoria formation, penetration, and invasive growth; mps 1 mutants are defective in penetration but are able to invade the host's tissue after wounding. Currently, pmk1/Fus3 homologues have been described in several plant-pathogenic fungi (Xu 2000), and in most cases, they play an essential role in pathogenesis, though the phenotypes of deletion mutants differ with respect to impact on vegetative properties such as conidiation, etc.

Here, we present for the first time a functional analysis of a pmk1/Fus3 homologue, cpmkl, which has been isolated from a biotrophic, highly organ-specific, non-appressoria-forming fungus, the ascomycete $C$. purpurea. We have obtained a knockout mutant showing a drastic phenotype: the inactivation of this signaling pathway has no impact on vegetative properties (growth, conidiation, and germination of conidia), but it renders the mutant completely nonpathogenic. The lack of detectable hyphae in the style tissue and the complete absence of any host reaction (the florets can produce normal karyopses; no browning occurs, as has been observed in the case of another set of apathogenic mutants defective in polygalacturonase activity [Oeser et al., in press]) indicates that no penetration of the host's cuticle occurs, although this is difficult to monitor 
because of the complex structure of the rye's highly branched stigma. The penetration process in the $C$. purpurea-rye interaction is not yet fully understood. Detailed transmission and scanning electron microscopic studies have never given any evidence for the presence of appressorialike structures (Tenberge 1999; K. B. Tenberge, unpublished data); penetration normally occurs shortly after germination of conidia, in the majority of cases, through the stigmatic hairs, but in rare cases, almost any other part of the rye floret can be used as a point of entry. Despite the lack of appressoria (the main target of the PMK1dependent pathway) in this system, the phenotype is almost identical to that of $\Delta p m k 1$ of $M$. grisea, indicating that the basic penetration mechanism could be related, in spite of the lack of apparent morphological differentiation. Alternatively, MAP kinase cascades represent evolutionary old signaling pathways involved in sensing the host's surface, initiating penetration programs that have been divergently adapted to the different hosts/organs involved. In addition, the cpmkl mutant cannot invade the host tissue after wounding; obviously, in the $C$. purpurea system, as in the foliar pathogens $M$. grisea $(\mathrm{Xu}$ and Hamer 1996), Colletotrichum lagenarium (Takano et al. 2000), Pyrenophora teres (Ruiz-Roldán et al. 2001), the necrotrophic fungus Botrytis cinerea (Zheng et al. 2000), and the root pathogen $F$. oxysporum (Di Pietro et al. 2001), the factors necessary for invasive growth are controlled by this Fus3 homologous signaling pathway.

Since only one pure $\Delta c p m k 1$ mutant was obtained (the second one, M1.245, carries an additional ectopic copy), the correlation between the observed phenotype and the deletion of cpmkl was confirmed by complementation of the mutant by the wild-type gene.

The functional equivalence of $c p m k 1$ and $p m k l$ was demonstrated by the interspecies complementation experiment: cpmkl fully restored the wild-type phenotype in a $\Delta p m k l$ mutant, even under the control of the $C$. purpurea promoter. This was not to be expected, since in a comparable experiment with various hydrophobin genes for complementation of the $\Delta m p g 1 \mathrm{mu}-$ tant of $M$. grisea, an $M$. grisea promoter fusion was a prerequisite for successful complementation in most cases (Kershaw et al. 1998). Little is known about the transcriptional regulation of the pmkl-like genes. In contrast to $p t k l$ from P. teres (RuizRoldán et al. 2001), which is constitutively expressed, Xu (2000) reported that the $M$. grisea pmkl protein is particularly abundant during appressoria differentiation. Differences between the temporal expression patterns of pmkl-like genes could contribute to the partial complementation of the pathogenic behavior of the $\Delta f m k l$ mutant from $F$. oxysporum by $M$. grisea pmkl and to the dose-dependent complementation of its invasive growth (Di Pietro et al. 2001). However, pmkl fully restores the ability of the Colletotrichum lagenarium $\Delta \mathrm{cmkl}$ mutant to develop infection structures (Takano et al. 2000), indicating that the regulatory pathways controlling the expression of both genes in these two pathogens are similar; this is not surprising, since they have comparable appressoria-dependent infection processes. On the other hand, because of the completely different infection strategies, the obviously strict conservation of the functional homology of the $M$. grisea and the $C$. purpurea systems was not to be expected. The conservation is high enough to allow a correct expression of the gene in $M$. grisea, even under the control of the $C$. purpurea promoter, and the full complementation of the pmkl deficiency with a single-copy integration of cpmkl.

In contrast to yeast (and higher eukaryotes), the analysis of MAP kinase cascades in filamentous fungi is still in its infancy. Among the few upstream elements of the tripartite Fus3/Kss1like pathways known in filamentous fungi are the MAPK kinase (MAPKK) Ubc5 (Fuz7) from Ustilago maydis (Andrews et al.
2000), the CgMEK1 from Colletotrichum gloeosporioides (Kim et al. 2000), and the MAPKK kinase (MAPKKK) Ubc4 from $U$. maydis (Andrews et al. 2000). As in the filamentous growth of $S$. cerevisiae, which is controlled by both the cAMP/PKA- and Kss1-dependant pathways, cAMP signaling acts in parallel to the PMK1 pathway to trigger fungal differentiation and pathogenesis in several filamentous fungi. In $M$.
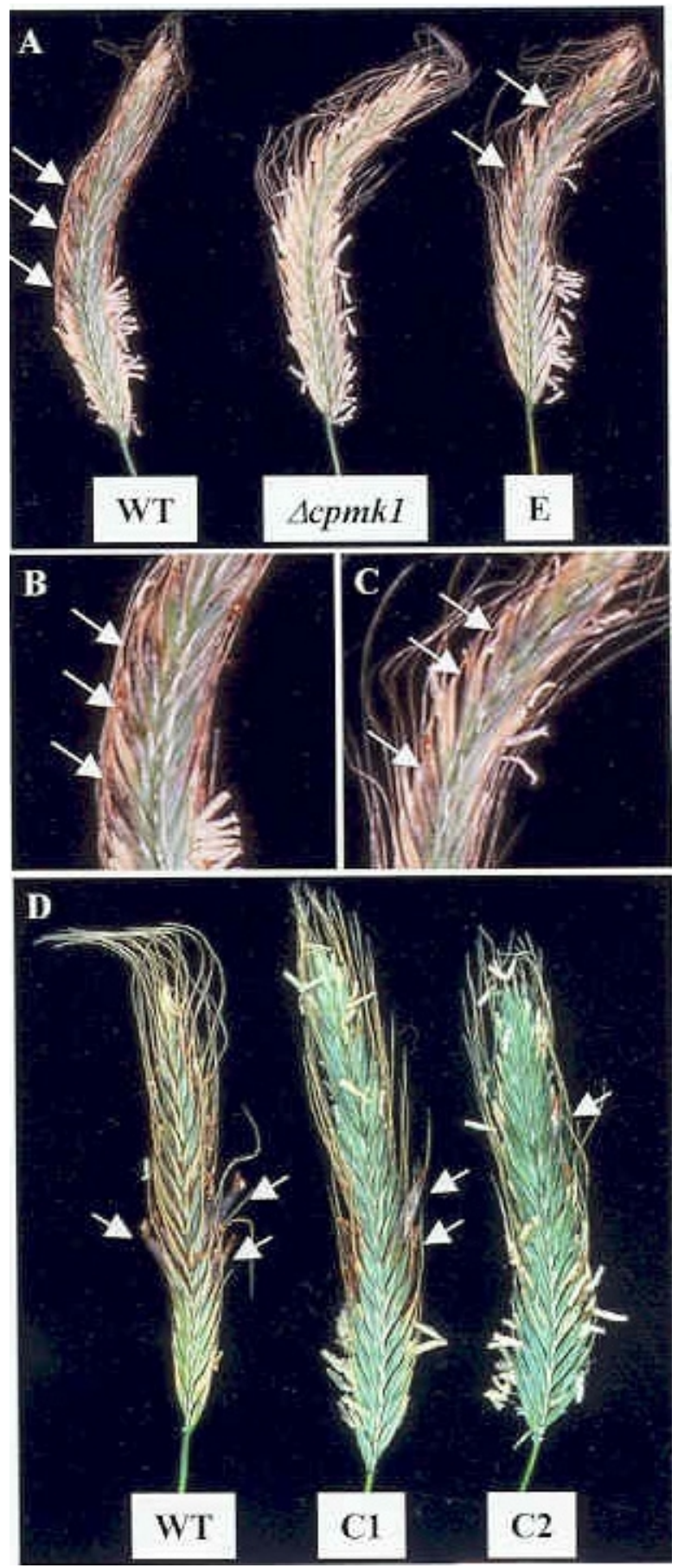

Fig. 4. Pathogenicity assay on rye plants. Rye florets were infected with conidia from the wild-type strain (WT), the $\Delta c p m k 1$ mutant M1.5 $(\Delta c p m k 1)$, the transformant M1.28 carrying an ectopic integration of the replacement construct (E), or the M1.5-complemented transformants M1C.6 (C1) and M1C.8 (C2) carrying ectopic copies of the wild-type gene cpmk1 ( $\Delta$ cpmk1/cpmk1). A, Rye ears infected with the wild type, the knock-out mutant, and the ectopic transformants after 3 weeks. B and C, Magnifications of the ears infected with the wild type and the ectopic transformant, respectively. D, Ears infected with the wild type and complemented transformants after 4 weeks. Arrows indicate the positions of sclerotia. 
grisea, cAMP was shown to trigger the differentiation of appressoria, and the $\Delta p m k 1$ mutants still exhibited swelling but did not form melanized appressoria in response to the presence of exogenous cAMP (Xu and Hamer 1996). U. maydis uacl mutants, which are affected in adenylate cyclase activity, show a constitutive filamentous growth and are impaired in pheromone response and virulence. The MAPK gene $u b c 3$ was identified as a suppressor mutation of the uacl phenotype and was cloned by complementation (Mayorga and Gold 1999). The $\Delta u b c 3$ mutant is defective in filamentous growth; the solopathogenic haploid strain $\Delta k p p 2(k p p 2=u b c 3)$ showed a reduced virulence on maize (Müller et al. 1999). In contrast, the formation of appressoria in $P$. teres, which could not be induced in the $\Delta p t k 1$ mutant by the addition of cAMP, seems to strictly depend on the PTK1 MAPK pathway (Ruiz-Roldán et al. 2001).

With the exception of the transcription factor Prf1 from $U$. maydis (Hartmann et al. 1996; Kahmann et al. 1999), not much information is available about the proteins acting downstream of the PMK1-like MAPKs. In Colletotrichum lagenarium, expression studies have revealed putative target genes: the temporal transcription patterns of three melanin biosynthetic genes were affected in the nongerminating conidia of the $\Delta \mathrm{cmkl} \mathrm{mu-}$ tant (Takano et al. 2000) and the mRNA levels of an endopectate lyase were greatly reduced in the $\Delta f m k l$ mutant from $F$. oxysporum (Di Pietro et al. 2001). Interestingly, the expression of an endopolygalacturonase gene in $S$. cerevisiae depends on the Kss1 pathway (Madhani et al. 1999), suggesting that the transcriptional control of genes coding for secreted enzymes may involve comparable regulatory pathways in yeast and filamentous fungi.

The identification of a signaling pathway controlling pathogenicity in $C$. purpurea on rye opens several new pathways for the study of this interaction: by comparison of gene expression in the wild type and the $\Delta c p m k l$ mutant, the identification of target genes is possible, thus allowing a more detailed understanding of this specialized system. In a first approach, the genes that have been identified in our lab will be tested in order to determine whether they are under the control of this MAP kinase pathway (e.g., polygalacturonase/cellulase/xylanase genes and several active-oxygen-scavenging enzyme genes). Furthermore, a random approach using a general differential screening system is also possible. The use of a reporter gene linked to a promoter of a target gene could allow the identification of signals triggering this pathway, as well as signaling components upstream of CPMK1, such as the receptor or receptors. We recently isolated a $C$. purpurea Slt2 homologue, called cpmk2, that shows high homology to the $M$. grisea gene mps 1; the joint analysis of these MAP kinase cascades will yield valuable insights into the highly specialized infection process of the biotrophic fungus $C$. purpurea.

\section{MATERIALS AND METHODS}

\section{Strains and culture conditions.}

The wild-type $C$. purpurea (Fr.:Fr.) Tul. strain used in these experiments was 20.1, a putative haploid derivative of standard field isolate T5, isolated from rye (Secale cereale L.; Hohenheim, Germany) and obtained by haploidization-inducing benomyl treatment (Hüsgen et al. 1999). For conidia harvesting and DNA isolation, mycelia were cultivated on Mantle agar (16 $\mathrm{g}$ of agar per liter) with $100 \mathrm{~g}$ of sucrose per liter (Mantle and Nisbet 1976) at $28^{\circ} \mathrm{C}$ for 12 to 14 days. The fertile ricepathogenic $M$. grisea strain Guy11 (Notteghem and Silué 1991) was used as a wild-type strain in this study, and the $\Delta p m k 1$ mutant strain nn78 (Xu and Hamer 1996) was used for
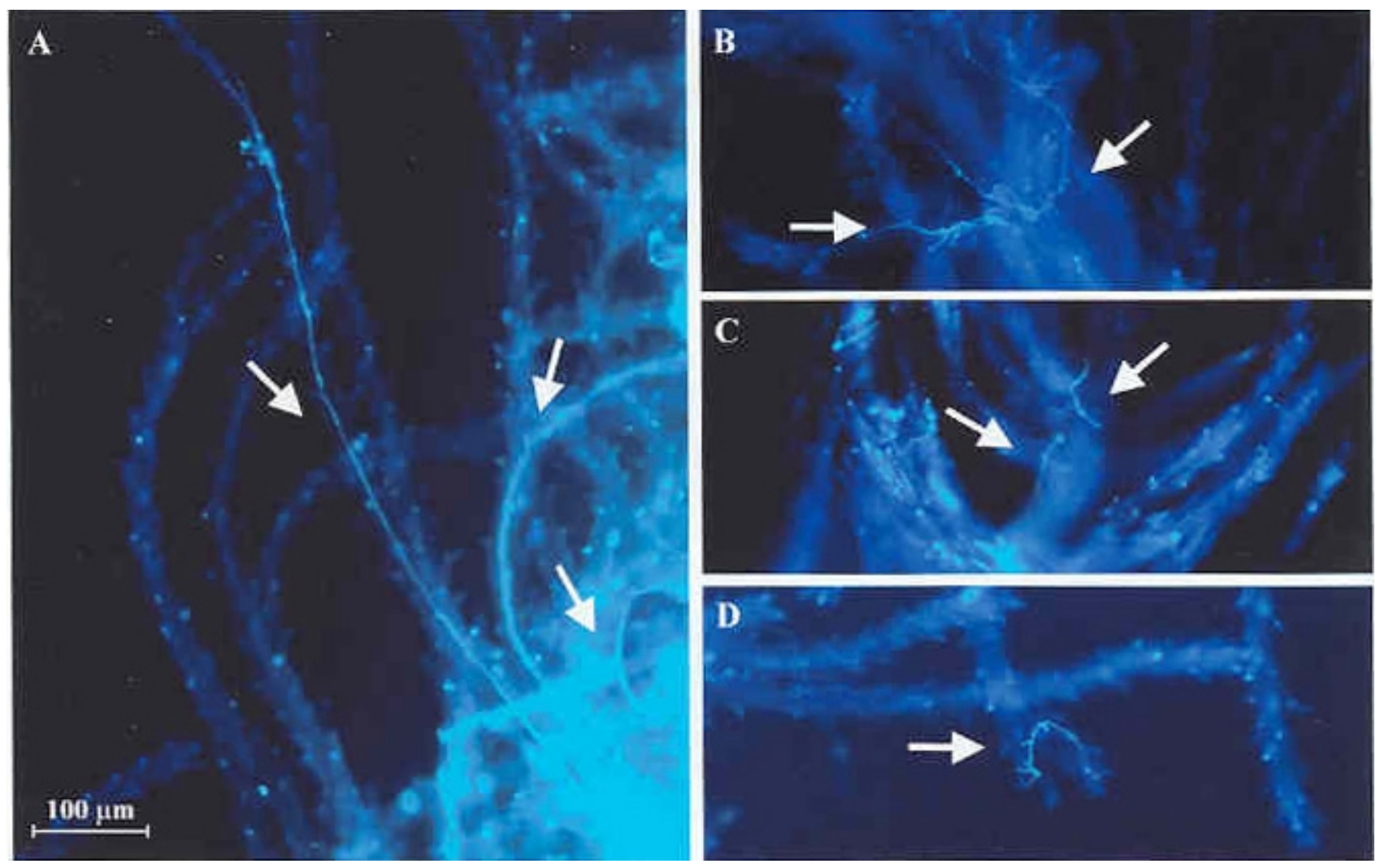

Fig. 5. Effect of the inactivation of cpmkl on the ability of Claviceps purpurea to penetrate and colonize rye ovaries. Rye ovaries were infected in vitro with conidial suspensions from the $\mathbf{A}$, wild-type and $\mathbf{B}, \mathbf{C}$, and $\mathbf{D}, \Delta$ cpmk 1 mutant M1.5 strains. The ovaries were collected at 5 days postinoculation, stained with aniline blue, and observed using epifluorescence microscopy. Arrows indicate the positions of hyphae. 
the complementation experiments. The fungus was grown routinely on complete medium (Talbot et al. 1993) and stored as described by Kershaw and colleagues (1998). Escherichia coli strain TOP10F' (Invitrogen, Carlsbad, CA, U.S.A.) was used for all the subcloning experiments. E. coli strains LE392 and XL1Blue (Stratagene, La Jolla, CA, U.S.A.) were employed for the propagation of $C$. purpurea genomic and cDNA lambda clones, respectively.

\section{Nucleic acid extraction and analysis.}

Standard recombinant DNA methods were performed according to Sambrook and colleagues (1989) and Ausubel and colleagues (1987). Genomic DNA from C. purpurea was prepared from lyophilized mycelium according to Cenis (1992). $M$. grisea genomic DNA extraction was performed according to Daboussi and colleagues (1989). For Southern blot analysis, 5 to $10 \mu \mathrm{g}$ of restriction-digested chromosomal DNA or PCR products were electrophoresed in 0.8 to $1.6 \%$ agarose gels with salt-free buffer (Sambrook et al. 1989), blotted onto positively charged nylon filters (Hybond-N+; Amersham, Braunschweig, Germany), and hybridized to radioactivity-labeled DNA probes in Denhardt's hybridization solution (Sambrook et al. 1989). Filters were washed for $10 \mathrm{~min}$ in $2 \times \mathrm{SSC}(1 \times \mathrm{SSC}$ is $0.15 \mathrm{M}$ $\mathrm{NaCl}$ plus $0.015 \mathrm{M}$ sodium citrate), $0.1 \%$ sodium dodecyl sulfate (SDS) and for $10 \mathrm{~min}$ in $1 \times \mathrm{SSC}, 0.1 \% \mathrm{SDS}$. The hybridization and washing temperatures used were 57 and $65^{\circ} \mathrm{C}$ for low and high stringency conditions, respectively. DNA sequencing was carried out as described by Moore and colleagues (2002). Protein and DNA sequence alignment, editing, and organization were done with DNA Star (Madison, WI, U.S.A.). Sequence analysis was done using BLAST at $\mathrm{Na}-$ tional Center for Biotechnology Information, Bethesda, MD, U.S.A. (Altschul et al. 1990).

PCR was done as described by Sambrook and colleagues (1989), using the Red Taq Polymerase (Sigma, Milwaukee, WI, U.S.A.). All primers were synthesized by MWG-Biotech (München, Germany). The amplification products were cloned with the PCR 2.1 TOPO-Cloning Kit from Invitrogen.

\section{Cloning of cpmk1.}

A cpmk1 490-bp internal fragment was amplified by PCR with the degenerate primers MAPK5a (5' GARATGAAGCTVCTBCGRTACTTYAAYC 3') and MAPK4 (5' CATDATYTCDGGDGCDCGRATCC 3') ( $\mathrm{R}=\mathrm{A}$ or $\mathrm{G} ; \mathrm{V}=\mathrm{A}, \mathrm{C}$, or $\mathrm{G} ; \mathrm{B}=\mathrm{C}, \mathrm{G}$, or $\mathrm{T} ; \mathrm{Y}=\mathrm{C}$ or $\mathrm{T}$; and $\mathrm{D}=\mathrm{A}, \mathrm{G}$, or $\mathrm{T}$ ) and genomic DNA from C. purpurea strain 20-1. The amplification product, cloned into the PCR 2.1 TOPO vector (Invitrogen), was excised by EcoRI digestion and used as a probe to screen a genomic library of strain T5 (Smit and Tudzynski 1992) by plaque filter hybridization (Sambrook et al. 1989). Out of the 6,000 lambda clones screened, seven hybridized to the PCR probe and were further purified (Sambrook et al. 1989). They all carry overlapping genomic region, as revealed by restriction and Southern blot analyses. A 6.9-kb BamHI fragment from the phage no. 2, carrying the complete cpmkl gene, was cloned into pUC19, giving the pMKB2 plasmid, and completely sequenced. The 490-bp PCR fragment was also used as a probe to screen a $C$. purpurea cDNA library ( $\lambda$ ZAP express, Stratagene) (S. Moore, unpublished data) by plaque filter hybridization (Sambrook et al. 1989); two cDNA clones were obtained, excised, and sequenced.

\section{Expression studies.}

For expression analysis during the parasitic cycle of ergot, total RNA from rye ovaries infected for 5, 10, 15, and 20 days with $C$. purpurea wild-type strain and from noninfected ovaries was prepared by using the RNAgents total RNA Isolation Sys- tem from Promega (Madison, WI, U.S.A.). RT-PCR was carried out as described previously (Müller et al. 1997). One microgram of mRNA was converted to cDNA by using the reversetranscriptase "Superscript" (Gibco BRL, Grand Island, NY, U.S.A.) and the primer K10 (5' GGCCTTCAACGCACGCAGCGTCTGG 3'), binding 635 bp downstream of the cpmkl predicted start codon; the product was taken up in $21 \mu \mathrm{lof}$ double-distilled $\mathrm{H}_{2} \mathrm{O}$. The PCR was done with $5 \mu$ of cDNA template using $1 \mu \mathrm{M}$ gene-specific primers $\mathrm{K} 9$ (5' GCTACCCCGCCGAACCCTCCCC $3^{\prime}$ ), binding 55 bp upstream of the translation initiation site, and K10 (Fig. 2, top). RT-PCR expression analysis of a class II hydrophobin gene, cphl (S. Moore and P. Tudzynski, unpublished data), was used as a control with the gene-specific primers RTHF ( $5^{\prime}$ TCCTTCATCATCTCCATCATGG 3') and RTHR (5' GAAATGCACAGAACACCCTGTC $3^{\prime}$ ).

\section{Construction of the replacement and complementation vectors.}

For constructing the cpmkl replacement vector, the genomic region located between -536 and $+473 \mathrm{bp}$, respective to the predicted start codon, was amplified using PCR and subcloned with the SacII-NotI sites of the vector PCR 2.1 TOPO downstream of the phleomycin resistance cassette (ble) into the corresponding SacII-NotI restriction sites of the pAN8-1UM vector, giving the $\mathrm{pM} 1 \mathrm{P}$ plasmid. The $\mathrm{pM} 1 \mathrm{R}$ replacement plasmid was obtained following the cloning of a 860-bp fragment corresponding to the region -196 to $+666 \mathrm{bp}$, respective to the stop codon, excised from the pMKB2 vector with a HindIII digest upstream of the fungal selection marker (ble) into the pM1P vector. The linear replacement construct was excised with a SacII-KpnI restriction and used to transform the $C$. purpurea wild-type strain 20-1 (Fig. 3A). The complementation vector was obtained by cloning a 3.6-kb XbaI-SacI fragment from the pMKB2 plasmid into the corresponding restriction sites of the pCB1635 vector (Sweigard et al. 1997), carrying a resistance cassette to the glufosinate. The plasmid obtained, called pM1CXS, carries the coding sequence of $c p m k 1,1.0$ and $1.1 \mathrm{~kb}$ of its $5^{\prime}$ and $3^{\prime}$ flanking regions, respectively. The circular vector was used to transform the $C$. purpurea $\Delta$ cpmkl mutant strain M1.5.

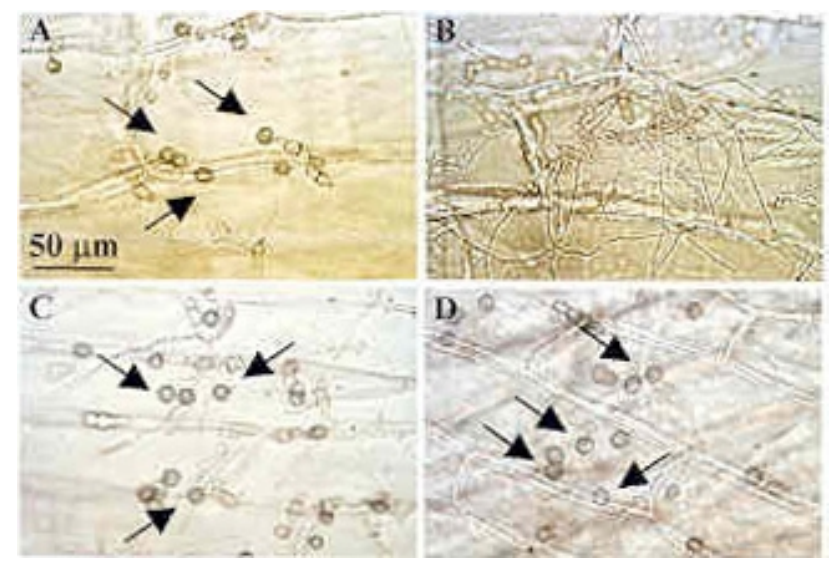

Fig. 6. Complementation of the appressoria differentiation defect of the $\Delta p m k 1$ mutant strain of Magnaporthe grisea by Claviceps purpurea cpmk1. Thirty- to fifty-microliter droplets of conidial suspensions from the $M$. grisea strains A, Guy 11 (wild type) and $\mathbf{B}, \mathrm{nn} 78$ ( $\Delta p m k 1)$, and $\mathbf{C}$ and $\mathbf{D}$, the nn78 transformants carrying the cpmk1 gene from $C$. purpurea $(\Delta p m k 1 /$ cpmkl) were placed on the hydrophobic face of onion epidermis previously flattened on glass slides and incubated with humidity overnight at room temperature. Appressoria formation was followed by using light microscopy. Arrows indicate appressoria. 
Transformation and analysis of fungal transformants.

Transformation of $C$. purpurea was performed according to Smit and Tudzynski (1992), with the following modifications: the recipient strains, 20-1 and M1.5, were grown for 3 days on cellophane sheets on Mantle agar (instead of liquid culture). For the generation of protoplasts, $10 \mathrm{mg}$ of Lysing Enzyme (Sigma) per $\mathrm{ml}$ and $2.5 \mathrm{mg}$ of Driselase (Sigma) per $\mathrm{ml}$ were used instead of Novozym (Interspex, Foster City, CA, U.S.A.).

For the selection of phleomycin-resistant transformants, the protoplasts were mixed with BII agar medium (Esser and Tudzynski 1978) and modified for transformation (BII/8: $\mathrm{pH} 8$, lacking $\mathrm{Fe}$ and containing $20 \%$ saccharose and $12 \mathrm{~g}$ of agar per liter). After $4 \mathrm{~h}$ of regeneration at $28^{\circ} \mathrm{C}$, the protoplasts were overlayed with $10 \mathrm{ml}$ of BII/8 containing $100 \mu \mathrm{g}$ of phleomycin per ml (Cayla, Toulouse, France; final concentration of 33 $\mu \mathrm{g} / \mathrm{ml}$ ) and $16 \mathrm{~g}$ of agar per liter. After 3 to 5 days of growth at $28^{\circ} \mathrm{C}$, phleomycin-resistant colonies were transferred to $\mathrm{BII} / 8$ plates containing $100 \mu \mathrm{g}$ of phleomycin per $\mathrm{ml}$ and subjected to at least one round of single-spore isolation to obtain homokaryotic transformants. In order to obtain glufosinate-resistant transformants, Czapek Dox agar (Merck, Darmstadt, Germany) modified for transformation ( $\mathrm{pH} \mathrm{5.2,} \mathrm{lacking} \mathrm{glucose} \mathrm{and} \mathrm{con-}$ taining $20 \%$ saccharose) was mixed with the transformed protoplasts. A 10-ml overlay of Czapek Dox agar containing $600 \mu \mathrm{g}$ of glufosinate per ml (glufosinate-ammonium PESTANAL; Riedel-de Haën, Rdh Laborchemikalien GmbH \& Co. KG, Seelze, Germany; final concentration of $200 \mu \mathrm{g} / \mathrm{ml}$ ); was added after $24 \mathrm{~h}$ of regeneration at $28^{\circ} \mathrm{C}$. After 10 days incubation at $28^{\circ} \mathrm{C}$, the glufosinate-resistant colonies were transferred to modified Czapek Dox plates ( $\mathrm{pH} 5.2,10 \%$ saccharose, no glucose) containing $300 \mu \mathrm{g}$ of glufosinate per $\mathrm{ml}$.

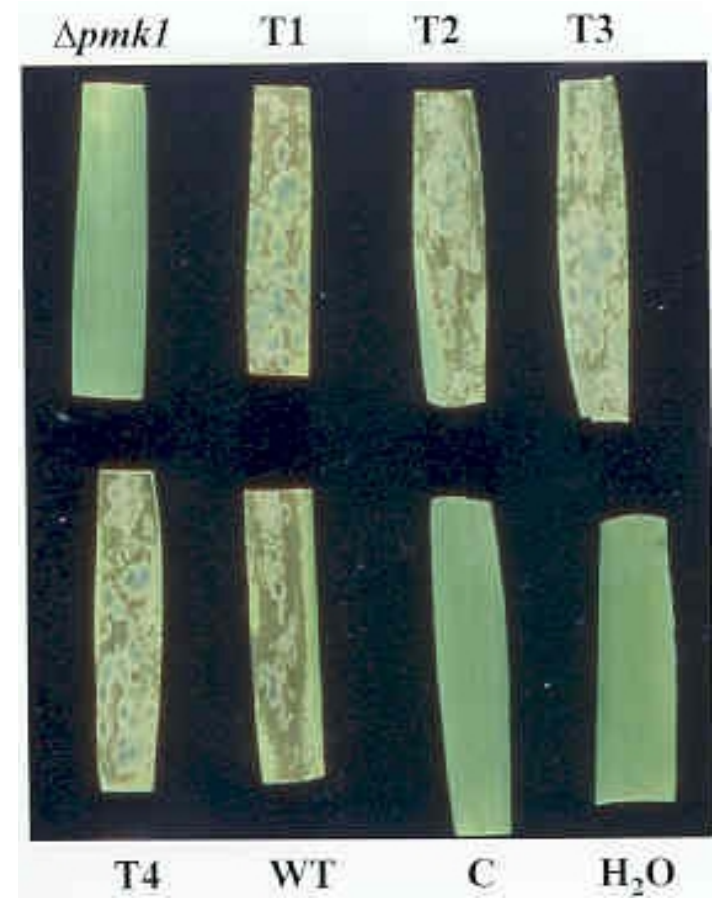

Fig. 7. Complementation of the pathogenicity defect of the $\Delta p m k 1 \mathrm{mu}$ tant strain from Magnaporthe grisea on barley by Claviceps purpurea cpmk1. Conidial suspensions from the M. grisea strains Guy 11 (wild type, WT), nn78 ( $\Delta p m k 1)$, the nn78 transformants carrying the cpmk1 gene from C. purpurea ( $\Delta$ pmk1/cpmk1, T1 to T4), and the nn78 control transformants carrying the pCB1635 vector (C) were spread on the surface of barley leaves in vitro and incubated at $26^{\circ} \mathrm{C}$. The picture was taken at 5 days postinoculation. A control with water $\left(\mathrm{H}_{2} \mathrm{O}\right)$ was performed in parallel.
The phleomycin-resistant transformants carrying a homologous integration of the replacement construct were identified by PCR with the primers K5 (5' GTGTCCACTGTCCTCGTCGCC $3^{\prime}$ ) and pAN2 (5' CCGTAACACCCAATACGCCGG 3') (Fig. 3A) and 10 to $100 \mathrm{ng}$ of genomic DNA. The presence of the wild-type gene copy in the $\Delta c p m k 1$ mutants was checked with the primers K5 and K7 (5' GCTGCCGAACGAGCCAAGCCG $3^{\prime}$ ), which give rise to a 1,480-bp fragment with the wild-type strain. The presence of the wild-type cpmkl coding sequence in the M1.5 transformants $(\Delta c p m k 1 / c p m k 1)$ was verified by PCR with the primers K11 (5' GGAGGTATGTACTCCGTAGGTAGG 3') and K12 (5' GGCCCTGTCAGGACGGACGAGC $3^{\prime}$ ), binding to the regions 579 bp upstream of the cpmk1 translation initiation site and $141 \mathrm{bp}$ downstream of the stop codon. The resistance of the M1.5 transformants to phleomycin was tested on BII/8 agar. The identity of M1.5 ( $\Delta c p m k 1)$ as the recipient strain was confirmed by Southern blot analysis of the M1C.6 and M1C.8 transformants.

Preparation of the protoplasts and transformation of $M$. grisea were performed according to Daboussi and colleagues (1989). Transformants were selected for glufosinate resistance in modified "CM" medium (Sweigard et al. 1992) containing $20 \%$ saccharose and $40 \mu \mathrm{l}$ of glufosinate per ml. Transformants were purified by monoconidial isolation and analyzed by Southern blot. Part of the $M$. grisea pmkl gene, corresponding to the region +358 to +1179 bp respective to the start codon, was amplified with the primers MK1 (5' CTCCGCGAGATGAAGCTGCTCCGG $3^{\prime}$ ) and MK2 (5' CGACGGTGATGGGCTTGACGGGG $3^{\prime}$ ) and with genomic DNA from strain Guy 11 as a template. The 820-bp amplification product was cloned into the PCR2.1 TOPO vector (Invitrogen) and used as a probe to reveal the $p m k l$ wild-type gene copy.

\section{C. purpurea pathogenicity assays.}

Rye plants were cultivated in growth chambers as described by Smit and Tudzynski (1992). Florets of blooming ears (60 to 80 per ear; altogether 40 ears in five independent experiments) were inoculated with conidial suspensions as described by Tenberge and colleagues (1996). In order to avoid cross-contamination, directly after inoculation, the ears were covered with paper bags equipped with cellophane windows. To introduce the fungus inside the plant (wounding test), rye florets were infiltrated with the conidial suspension by using a syringe with a needle ( 25 gauge $\times 5 / 8$ in., U-40 insulin, Terumo syringe; Terumo Europe N. V., Leuven, Belgium). Pictures were taken 3 to 4 weeks postinoculation.

\section{Aniline blue staining}

\section{and fluorescence microscopy observations.}

An in vitro infection system was used (modified from Heslop-Harrison and Heslop-Harrison 1981; J. Scheffer, unpublished data). Rye ovaries were isolated from blooming rye ears and put onto Hoagland solution (Hewitt 1966; Hoagland and Arnon 1938) modified for barley shoot culture (for 1 liter: MES buffer, $5 \mathrm{ml}$ [2-morpholino ethanesulfonic acid, $19.5 \mathrm{~g} /$ liter; $\mathrm{NaOH}, 2.0$ g/liter; $\mathrm{pH}$ 6.5]; $\mathrm{Ca}\left(\mathrm{NO}_{3}\right)_{2} 4 \mathrm{H}_{2} \mathrm{O}, 94 \mathrm{mg}$; $\mathrm{KNO}_{3}, 66 \mathrm{mg} ; \mathrm{MgSO}_{4} 7 \mathrm{H}_{2} \mathrm{O}, 52 \mathrm{mg} ; \mathrm{KH}_{2} \mathrm{PO}_{4}, 38 \mathrm{mg} ; \mathrm{H}_{3} \mathrm{BO}_{3}$, $2.86 \mathrm{mg} ; \mathrm{ZnSO}_{4} 7 \mathrm{H}_{2} \mathrm{O}, 0.22 \mathrm{mg} ; \mathrm{CuSO}_{4} 5 \mathrm{H}_{2} \mathrm{O}, 0.1 \mathrm{mg}$; $\mathrm{Na}_{2} \mathrm{MoO}_{4} 2 \mathrm{H}_{2} \mathrm{O}, 0.05 \mathrm{mg}$; and FeEDTA, $12 \mathrm{mg}$ ) and solidified with $16 \mathrm{~g}$ of agar per liter. Stigmas were inoculated with suspensions containing $2 \times 10^{6}$ conidia per $\mathrm{ml}$ by using cotton tips and were incubated at room temperature for 5 days. The $\mathrm{KOH}-$ aniline blue staining of the fungus was realized as described by Hood and Shew (1996), except that the ovaries were incubated in $1 \mathrm{M} \mathrm{KOH}$ overnight at room temperature. The infected ovaries were observed using epifluorescence microscopy (Microscope Leica DMRBE [Leica Instruments, Heerbrugg, 
Switzerland] with PixelFly Digital camera [PCO Computer Optics GmbH, Kelheim, Germany], filter block A [band pass filter $\{\mathrm{BP}\} 340-380$, reflection short pass filter $\{\mathrm{RSP}\} 400$, long pass filter \{LF\} 425], UV light 340 to $380 \mathrm{~nm}$ ).

\section{Appressoria differentiation assays and barley infection tests.}

$M$. grisea conidia were collected in water, filtered through glass wool, centrifuged for $10 \mathrm{~min}$ at $5,000 \times g$ and $4^{\circ} \mathrm{C}$, and resuspended into water. The final concentration of the spores was adjusted to $2 \times 10^{4}$ per $\mathrm{ml}$.

Appressoria differentiation tests were performed using two types of hydrophobic surfaces, vinyl slides Rinzl (PolyLabo, Strasbourg, France) and onion epidermis. Prior to use, the peeled inner epidermis of onion was washed for $5 \mathrm{~min}$ in chloroform and then in water and flattened onto glass slides so that the hydrophobic sides faced upward (M. J. Kershaw and N. J. Talbot, personal communication). The slides, placed into petri dishes, were inoculated with 30 - to $50-\mu$ d droplets of conidial suspensions and incubated overnight at room temperature under high humidity. Appressoria differentiation was followed by using light microscopy. Barley infection tests were performed as described by Clergeot and colleagues (2001). Seedlings from the barley cultivar Express (Aventis Cropscience, Lyon, France) were cultivated for 2 weeks at $12^{\circ} \mathrm{C}$ (with $12 \mathrm{~h}$ of light per day). Leaf segments $3 \mathrm{~cm}$ long were placed onto agar plates (1\%) containing $2 \mathrm{mg}$ of kinetin per liter (Sigma) and wetted with water by using cotton tips. The conidial suspensions were spread on the leaf surface in the same way. The lesions appeared and started to sporulate after 4 to 7 days of incubation at $26^{\circ} \mathrm{C}$.

\section{ACKNOWLEDGMENTS}

We thank J. Scheffer for advice with the in vitro infection system of rye, S. Moore for carefully reading, and A. Kammerahl for typing the manuscript. The support of the European Commission (TMR network "CEREPAT") is gratefully acknowledged.

\section{LITERATURE CITED}

Altschul, S. F., Gish, W., Miller, W., Myers, E. W., and Lipman, D. J. 1990. Basic local alignment search tool. J. Mol. Biol. 215:403-410.

Andrews, D. L., Egan, J. D., Mayorga, M. E., and Gold, S. E. 2000. The Ustilago maydis $u b c 4$ and $u b c 5$ genes encode members of a MAP kinase cascade required for filamentous growth. Mol. Plant-Microbe Interact. 13:781-786.

Ausubel, F. M., Brent, R., Kingston, R. E., Moore, D. D., Seidmann, J. G., Smith, J. A., and Struhl, K. 1987 (Looseleaf). Current Protocols in Molecular Biology. John Wiley and Sons, New York.

Cenis, J. L. 1992. Rapid extraction of fungal DNA for PCR amplification. Nucleic Acids Res. 20:2380.

Clergeot, P. H., Gourgues, M., Cots, J., Laurans, F., Latorse, M. P., Pépin, R., Tharreau, D., Notteghem, J. L., and Lebrun, M. H. 2001. PLS1, a gene encoding a tetraspanin-like protein, is required for penetration of rice leaf by the fungal pathogen Magnaporthe grisea. Proc. Natl. Acad. Sci. U.S.A. 98:6963-6968.

Daboussi, M. J., Djeballi, A., Gerlinger, C., Blaiseau, P. L., Bouvier, L., Cassan, M., Lebrun, M.-H., Parisot, D., and Brygoo, Y. 1989. Transformation of seven species of filamentous fungi using the nitrate reductase gene of Aspergillus nidulans. Curr. Genet. 15:453-456.

Di Pietro, F., García-Maceira, I., Méglecz, E., and Roncero, M. I. G. 2001. A MAP kinase of the vascular wilt fungus Fusarium oxysporum is essential for root penetration and pathogenesis. Mol. Microbiol. 39(5):1140-1152.

Esser, K., and Tudzynski, P. 1978. Genetics of the ergot fungus Claviceps purpurea. I. Proof of monoecious life cycle and segregation patterns for mycelial morphology and alkaloid production. Theor. Appl. Genet. 53:145-149.

Garre, V., Müller, U., and Tudzynski, P. 1998a. Cloning, characterization, and targeted disruption of cpcat1, coding for an in planta secreted catalase of Claviceps purpurea. Mol. Plant-Microbe Interact. 11:772783.

Garre, V., Tenberge, K. B., and Eising, R. 1998b. Secretion of a fungal extracellular catalase by Claviceps purpurea during infection of rye: Putative role in pathogenicity and suppression of host defense. Phytopathology 88:744-753.

Giesbert, S., Lepping, H.-B., Tenberge, K. B., and Tudzynski, P. 1998. The xylanolytic system of Claviceps purpurea: Cytological evidence for secretion of xylanases in infected rye tissue and molecular characterization of two xylanase genes. Phytopathology 88:1020-1030.

Hartmann, H., Kahmann, R., and Bölker, M. 1996. The pheromone response factor coordinates filamentous growth and pathogenicity in Ustilago maydis. EMBO (Eur. Mol. Biol. Organ.) J. 15:1632-1641.

Heslop-Harrison, J., and Heslop-Harrison, Y. 1981. The pollen-stigma interaction in the grasses. 2. Pollentube penetration and the stigma response in Secale. Acta Bot. Neerl. 30:289-307.

Hewitt, E. J. 1966. Sand and water culture methods used in the study of plant nutrition. Technical Communication No. 22 (Revised 2nd Edition) Commonwealth Bureau of Horticulture and Plantation Crops. The Eastern Press, Ltd., London.

Hoagland, D. R., and Arnon, D. I. 1938. The water-culture method for growing plants without soil. Univ. Calif. Agric. Exp. Stn. Circ. 347.

Hood, M. E., and Shew, H. D. 1996. Applications of KOH-aniline blue fluorescence in the study of plant-fungal interactions. Phytopathology 86:704-708.

Hüsgen, U., Büttner, P., Müller, U., and Tudzynski, P. 1999. Variation in karyotype and ploidy level among field isolates of Claviceps purpurea. J. Phytopathol. 147:591-597.

Kahmann, R., Basse, C., and Feldbrügge, M. 1999. Fungal-plant signalling in the Ustilago maydis-maize pathosystem. Curr. Opin. Microbiol. 2:647-650.

Kershaw, M. J., Wakley, G., and Talbot, N. J. 1998. Complementation of the Mpg1 mutant phenotype in Magnaporthe grisea reveals functional relationships between fungal hydrophobins. EMBO (Eur. Mol. Biol. Organ.) J. 17:3838-3849.

Kim, Y. K., Kawano, T., Li, D., and Kolattukudy, P. E. 2000. A mitogenactivated protein kinase kinase required for induction of cytokinesis and appressorium formation by host signals in the conidia of Colletotrichum gloeosporioides. Plant Cell 12:1331-1343.

Lengeler, K. B., Davidson, R. C., D’Souza, C., Harashima, T., Shen, W.C., Wang, P., Pan, X., Waugh, M., and Heitman, J. 2000. Signal transduction cascades regulating fungal development and virulence. Mol. Microbiol. Biotechnol. Rev. 64:746-785.

Madhani, H. D., Galitski, T., Lander, E. S., and Fink, G. R. 1999. Effectors of a developmental mitogen-activated protein kinase cascade revealed by expression signatures of signaling mutants. Proc. Natl. Acad. Sci. U.S.A. 96:12530-12535.

Mantle, P. G., and Nisbet, L. J. 1976. Differentiation of Claviceps purpurea in axenic culture. J. Gen. Microbiol. 93:321-334.

Mayorga, M. E., and Gold, S. E. 1999. A MAP kinase encoded by the $u b c 3$ gene of Ustilago maydis is required for filamentous growth and full virulence. Mol. Microbiol. 34:485-497.

Moore, S., de Vries, O., and Tudzynski, P. 2002. The major Cu,Zn SOD of the phytopathogen Claviceps purpurea is not essential for pathogenicity. Mol. Plant Pathol. 3:9-22.

Müller, P., Aichinger, C., Feldbrügge, M., and Kahmann, R. 1999. The MAP kinase Kpp2 regulates mating and pathogenic development in Ustilago maydis. Mol. Microbiol. 34:1007-1017.

Müller, U., Tenberge, K. B., Oeser, B., and Tudzynski, P. 1997. Cell, probably encoding a cellobiohydrolase lacking the substrate binding domain, is expressed in the initial infection phase of Claviceps purpurea on Secale cereale. Mol. Plant-Microbe Interact. 10:268-279.

Notteghem, J. L., and Silué, D. 1992. Distribution of the mating type alleles in Magnaporthe grisea populations pathogenic on rice. Phytopathology 82:421-424.

Oeser, B., Tenberge, K. B., Moore, S., Mihlan, M., Heidrich, P. M., and Tudzynski, P. Pathogenic development of Claviceps purpurea. In: Molecular Biology of Fungal Development. H. Osiewacz, ed. Marcel Dekker, New York. In press.

Ruiz-Roldán, M. C., Maier, F. J., and Schäfer, W. 2001. PTK1, a mitogenactivated-protein kinase gene, is required for conidiation, appressorium formation, and pathogenicity of Pyrenophora teres on barley. Mol. Plant-Microbe Interact. 14:116-125.

Sambrook, J., Fritsch, E. F., and Maniatis, T. 1989. Molecular Cloning: A Laboratory Manual, 2nd ed. Cold Spring Harbor Laboratory Press, Cold Spring Harbor, NY, U.S.A.

Schaeffer, H. J., and Webber, M. J. 1999. Mitogen-activated protein kinases: Specific messages from ubiquitous messengers. Mol. Cell. Biol. 19:2435-2444.

Smit, R., and Tudzynski, P. 1992. Efficient transformation of Claviceps purpurea using pyrimidine auxotrophic mutants cloning of the OMP decarboxylase gene. Mol. Gen. Genet. 234:297-305.

Sweigard, J., Chumley, F. G., and Valent, B. 1992. Cloning and analysis 
of Cut1, a cutinase gene from Magnaporthe grisea. Mol. Gen. Genet. 232:174-182.

Sweigard, J., Chumley, F. G., Caroll, A. M., Farrall, L., and Valent, B. 1997. A series of vectors for fungal transformation. Fungal Genet. Newsl. 44:52-53.

Takano, Y., Kikuchi, T., Kubo, Y., Hamer, J. E., Mise, K., and Furusawa, I. 2000. The Colletotrichum lagenarium MAP kinase gene CMKI regulates diverse aspects of fungal pathogenesis. Mol. Plant-Microbe Interact. 13:374-383.

Talbot, N. J., Ebbole, D. J., and Hamer, J. E. 1993. Identification and characterization of MPG1, a gene involved in pathogenicity from the rice blast fungus Magnaporthe grisea. Plant Cell 5:1575-1590.

Tenberge, K. B. 1999. Biology and life strategy of the ergot fungi. Pages 25-56 in: Medicinal and Aromatic Plants-Industrial Profiles, Vol. 6, Ergot-The Genus Claviceps. V. Křen and L. Cvak, eds. Harwood Academic Publishers, Amsterdam, The Netherlands.

Tenberge, K. B., Homann, V., Oeser, B., and Tudzynski, P. 1996. Structure and expression of two polygalacturonase genes of Claviceps purpurea orientated in tandem and cytological evidence for pecti- nolytic enzyme activity during infection of rye. Phytopathology 86:1084-1097.

ten Have, A., Tenberge, K. B., Benen, J. A. E., Tudzynski, P., Visser, J., and van Kann, J. A. L. 2001. The contribution of cell wall degrading enzymes to pathogenesis of fungal plant pathogens. In: The Mycota XI, Application in Agriculture. F. Kempken, ed. Springer-Verlag, Berlin. In press.

Tudzynski, P., Tenberge, K., and Oeser, B. 1995. Claviceps purpurea. Pages 161-187 in: Pathogenesis and Host Parasite Specificity in Plant Diseases: Histopathological, Biochemical, Genetic and Molecular Bases. Vol. IV: Eukaryotes. U. Singh, ed. Pergamon Press, New York.

$\mathrm{Xu}$, J.-R. 2000. MAP kinases in fungal pathogens. Fungal Genet. Biol. 31:137-152.

$\mathrm{Xu}$, J.-R., and Hamer, J. E. 1996. MAP-kinase and cAMP signaling regulate infection structure formation and pathogenic growth in the rice blast fungus Magnaporthe grisea. Genes Dev. 10:2696-2706.

Zheng, L., Campbell, M., Murphy, J., Lam, S., and Xu, J.-R. 2000. The $B M P 1$ gene is essential for pathogenicity in the gray mold fungus Botrytis cinerea. Mol. Plant-Microbe Interact. 13:724-732. 